\title{
Caracterização mecânica e microestrutural de um aço com baixo teor de carbono - SAE 1010
}

\author{
Mechanical and microstructural characterization of steel with low carbon - SAE 1010
}

\author{
Adonai dos Santos Neves, Andriel Sichi ${ }^{\dagger}$, Antônio Carlos Ramos Júnior ${ }^{\dagger}$, Claudio Domingos da Silva \\ Junior ${ }^{\dagger}$, Gelson Reis ${ }^{\dagger}$, Kleiton Gonçalves Lovati†, Vicente de Sousa ${ }^{\dagger}$, Ricardo de Freitas Cabra ${ }^{\dagger *}$
}

Como citar esse artigo. Neves, AS; Sichi, A; Ramos Júnior, AC; da Silva Júnior, CD; Reis, G; Lovati, KG; de Souza, V; Cabra, RF. Caracterização mecânica e microestrutural de um aço com baixo teor de carbono - SAE 1010. Revista Teccen. 2018 Jan/Jun.; 11 (1): 10-17.

\begin{abstract}
Resumo
Muitas são as aplicações para os aços que apresentam baixo teor de carbono. Itens como eletrodomésticos, partes de um automóvel, rodas, entre outras peças, são alguns pequenos exemplos de produtos confeccionados a partir dessa composição de aço, o qual pode compreender o limite de até 0,2 por cento de carbono em sua composição final. O SAE 1010, SAE 1018 e o SAE 1020 estão entre os aços com baixo teor de carbono mais amplamente utilizados. O aço SAE 1010 abriga em sua composição uma concentração de 0,10 por cento de carbono. O objetivo principal deste artigo é a caracterização mecânica e microestrutural de uma amostra de aço SAE 1010, realizando, para tanto, ensaios de tração, dureza Rockwell, microdureza Vickers, avaliação com de microscopia óptica e também de microscopia eletrônica de varredura (MEV). Os resultados obtidos utilizando-se a microscopia óptica e MEV apresentaram uma microestrutura caracterizada pela presença de ferrita $\alpha$ com alguns poucos pontos de perlita situados em seus contornos de grãos. Os testes de microdureza Vickers foram gerados com duas cargas de indentação e os testes de dureza Rockwell com uma carga de indentação, onde a média dessa carga foi de 99 HRB que, segundo a literatura atual analisada, este valor é compatível com o material aqui pesquisado. Palavras-Chave: Aço carbono; SAE 1010; Microdureza Vickers; Dureza Rockwell
\end{abstract}

\begin{abstract}
There are many applications for low carbon steels. Items such as appliances, parts of a car, wheels, among other parts, are some small examples of products manufactured with this type of steel, which can contain up to about 0.2 percent carbon in the final composition of the alloy. Among the most widely used low carbon steels are SAE 1010, SAE 1018 and SAE 1020. Steel SAE 1010 contains 0.10 percent carbon concentration in its composition. The main objective of this article is the microstructural and mechanical characterization of a SAE 1010 steel sample, through tensile tests, Rockwell hardness, Vickers microhardness, evaluation through optical microscopy and scanning electron microscopy (SEM). Analyzes obtained by optical microscopy and SEM came up with a microstructure characterized by the presence of $\alpha$ ferrite with a few pearlite points located in its grain boundaries. The Vickers microhardness tests were executed with two indentation loads and Rockwell hardness tests were executed with one indentation load, where the average of this load was 99 HRB which, according to the current literature analyzed, this value is compatible with the material here researched. Keywords: Carbon steel; SAE 1010; Vickers Microhardness; Rockwell Hardness.
\end{abstract}

\section{Introdução}

O material estudado neste artigo é o aço SAE 1010, uma liga composta basicamente pelos seguintes elementos químicos: Ferro (Fe), Carbono (C), Manganês $(\mathrm{Mn})$, Enxofre (S) e o Fósforo (P). Dependendo do processo siderúrgico, a concentração de cada elemento químico poderá variar, conforme mostrado na Tabela 1. Segundo Chiaverini (2008), “O Aço é uma liga de

\footnotetext{
Afiliação dos autores: $\uparrow$ Mestrado Profissional em Materiais do Centro Universitário de Volta Redonda - UniFOA - Av. Paulo Erlei Abrantes, 1325 - Bairro Três Poços, Volta Redonda - RJ - Brasil/Discentes do Mestrado Profissional em Materiais

屯 Mestrado Profissional em materiais do Centro Universitário de Volta Redonda - UniFOA - Av. Paulo Erlei Abrantes, 1325 - Bairro Três Poços, Volta Redonda - RJ -Brasil/Docente Responsável Doutor. Centro Universitário Geraldo Di Biase - UGB - Rodovia Benjamin Lelpo, Km 11, Barra do Piraí - RJ - CEP 27101-090, Brasil/Docente Responsável Doutor

* Email para correspondência: ricardo.cabral@foa.org.br
} 
ferro-carbono que compreende de $0,008 \%$ até $2,11 \%$ de carbono, aproximadamente, além de alguns elementos residuais dos processos de fabricação". Assim sendo, o aço SAE 1010 , que possui de $0,08 \%$ a $0,13 \%$ de teor de carbono, encontra-se inserido na definição de aço.

Com relação à composição química e processo siderúrgico, segundo Guerra, Figueroa-López \& Guevara-Morales (2017), aços considerados equivalentes na Europa e na América do Norte podem apresentar comportamentos diferentes quando submetidos a esforços mecânicos. Esse comportamento foi observado durante o processo de montagem de discos de embreagem fabricados em diferentes regiões do mundo.

$\mathrm{O}$ aço SAE 1010 possui uma relativa baixa resistência mecânica, porém sua resistência pode ser aumentada por meio de tratamentos térmicos, tais como têmpera e revenimento. Segundo Chiaverini (2008), esses tratamentos térmicos são um conjunto de operações onde os aços são submetidos, tendo a temperatura, o tempo, a atmosfera e a velocidade de esfriamento controlados.

O foco principal deste artigo é efetuar a caracterização mecânica e microestrutural da amostra de aço SAE 1010, realizando, para tanto, ensaios de tração, microdureza Vickers, dureza Rockwell, análise com Microscopia Óptica (MO) e Microscopia Eletrônica de Varredura (MEV) e comparar os valores obtidos com os mesmos encontrados na literatura visando confirmar a amostra como aço com baixo teor de carbono $(0,1 \%)$.

\section{Materiais e métodos}

Duas amostras do material aço SAE 1010, utilizadas no experimento, foram fornecidas pelo UniFOA, com medidas aproximadas de $20 \mathrm{~mm}$ largura e $2,5 \mathrm{~mm}$ espessura cada uma. Os corpos de prova foram preparados nos laboratórios do UniFoa, pelo processo de metalografia, nas seguintes etapas. Utilizou-se inicialmente uma Cortadora Metalográfica Teclago C M40 contendo disco abrasivo refrigerado para a retirada de uma amostra do corpo de prova. Em seguida, a amostra foi inserida na Embutidora Metalográfica Arotec PRE 30 $\mathrm{Mi}$, e sobre ela a resina para realização do embutimento com resina granulada (baquelite) a quente. O próximo passo foi submeter a amostra ao processo de lixamento utilizando uma Politriz Lixadeira Metalográfica Arotec com lixas de carbeto de silício de oito granulometrias diferentes, na ordem a seguir: $220,320,400,600,800$, 1000,1200 e 1500 , conforme a ASM Internacional (2002). Posteriormente, foi realizada a verificação do lixamento utilizando-se um Microscópio Metalográfico Invertido Opton TNM-07T-PL, com lente ocular de $10 \mathrm{x}$ e lentes objetivas de $10 \mathrm{x}, 20 \mathrm{x}$ e $40 \mathrm{x}$ para, comparando com o quadro comparativo de inclusões do laboratório UniFOA, averiguar se a superfície estava pronta, ou não, para a realização da microscopia ótica. Verificou-se que a superfície ainda não estava adequada, sendo necessário repetir o procedimento de lixamento. Em seguida, foi executado o polimento, empregando novamente uma Politriz Lixadeira Metalográfica Arotec, dessa vez com um feltro adequado para polimento, onde foi adicionado alumina com granulometrias diversas, e na ordem que segue $(1 \mu \mathrm{m}, 0,3 \mu \mathrm{m}$ e $0,05 \mu \mathrm{m})$, de forma a se obter uma superfície espelhada, que é o resultado esperado para se realizar o ataque químico, a última etapa do procedimento. Esta última etapa foi realizada submergindo a amostra por um período de 3 segundos num recipiente contendo o reagente químico Nital a $2 \%$ (solução de ácido nítrico em etanol) para revelação das microestruturas do aço. Após o ataque químico a amostra foi lavada e seca, de forma a isentála de impurezas que pudessem prejudicar a visualização da superfície do material atacado.

\section{Ensaio de Tração}

Conforme citado por Dieter, G.E. (2000), tensão de engenharia $(\sigma)$ e deformação de engenharia $(\varepsilon)$ são definidas pelas Equações (1) e (2).

$$
\sigma=\frac{F}{s_{0}}
$$

Onde:

$\mathrm{F}=$ força aplicada (carga);

$\mathrm{S}_{0}=$ área da seção inicial do corpo de prova onde a carga é diretamente aplicada.

$$
\epsilon=\frac{\mathrm{L}-L_{i}}{L_{i}}=\frac{\Delta \mathrm{L}}{L_{i}}
$$

Onde:

$\epsilon=$ Deformação; carga);

$\mathrm{L}_{\mathrm{i}}=$ Comprimento inicial (antes de aplicação da

$\mathrm{L}=$ Comprimento instantâneo (o comprimento final atingido no momento da ruptura é denominado $\mathrm{L}_{\mathrm{f}}$ ).

Conforme descrito na Tabela 2, as amostras foram medidas utilizando-se um micrômetro para determinação da espessura e um paquímetro para determinação da área útil, tratando-se de uma amostra de base $50 \mathrm{~mm}$.

Para a execução dos ensaios de tração foi empregado a norma ABNT NBR 6152 (2002), em dois corpos de prova que foram ensaiados em um 
Tabela1. Limites mínimo e máximo na composição do aço SAE 1010.

\begin{tabular}{|c|c|c|c|c|c|}
\hline & Aço & $\mathrm{C}(\%)$ & Mn (\%) & $S(\%)$ & $\begin{array}{c}P \\
(\%)\end{array}$ \\
\hline \multirow{2}{*}{ SAE 1010} & Mínimo & 0,08 & 0,3 & - & - \\
\hline & Máximo & 0,13 & 0,6 & 0,05 & 0,03 \\
\hline
\end{tabular}

Tabela 2. Determinação da área transversal ensaiada (largura x espessura) dos Corpos de Prova (CP) em $\mathrm{mm} 2$.

\begin{tabular}{|c|c|c|c|c|}
\hline \multirow[b]{2}{*}{ Medida } & \multicolumn{2}{|c|}{ CP1 } & \multicolumn{2}{|c|}{$\mathrm{CP2}$} \\
\hline & $\begin{array}{l}\text { Largura } \\
(\mathrm{mm})\end{array}$ & $\begin{array}{c}\text { Espessura } \\
\text { (mm) }\end{array}$ & $\begin{array}{c}\text { Largura } \\
\text { (mm) }\end{array}$ & $\begin{array}{c}\text { Espessura } \\
\text { (mm) }\end{array}$ \\
\hline $1^{\mathrm{a}}$ & 20,09 & 2,49 & 20,46 & 2,42 \\
\hline $2^{\mathrm{a}}$ & 20,06 & 2,61 & 20,41 & 2,46 \\
\hline Média & 20,08 & 2,55 & 20,44 & 2,44 \\
\hline Área Transversal $\left(\mathrm{mm}^{2}\right)$ & \multicolumn{2}{|c|}{51,20} & \multicolumn{2}{|c|}{49,87} \\
\hline
\end{tabular}

equipamento universal de ensaio mecânico, modelo DL 10000, marca EMIC, com capacidade máxima de $100 \mathrm{kN}$. Onde, cada amostra foi fixada ao Equipamento Universal de Ensaio com célula de carga de $500 \mathrm{kgf}$ com taxa de carregamento de $3 \mathrm{~mm} / \mathrm{min}$.

\section{Microdureza Vickers (HV)}

O teste de Microdureza Vickers (HV) do material foi executado com um Microdurômetro Time DHV 1000, com carga variável de 10 gf (grama força) a $1 \mathrm{kgf}$ (kilograma força), abrigando um penetrador piramidal de diamante com base quadrada e ângulo de $136^{\circ}$ entre suas faces, conforme definido pela norma ABNT NBR NM 188-1 (1999).

$\mathrm{O}$ valor de dureza é apresentado em relação à área impressa pela indentação com formato de uma Pirâmide invertida, onde a carga aplicada (medida em kgf) é dividida pela média ao quadrado das diagonais de indentação (medida $\mathrm{em}^{2}$ ), conforme mostrado na equação (3):

$$
\mathrm{HV}=\frac{1,8544 \mathrm{~F}}{\mathrm{~d}^{2}}
$$

Onde:

$\mathrm{F}=$ carga (em kgf);

$\mathrm{d}=$ média aritmética das diagonais $\mathrm{d}_{1}$ e $\mathrm{d}_{2}(\mathrm{em}$ $\mathrm{mm})$;

$\mathrm{HV}=$ microdureza Vickers.

Foram realizadas 20 indentações, sendo 10 indentações com carga de 300 gf e as outras 10 com carga de 500 gf, todas elas com duração de 15 segundos como tempo padrão de teste.

\section{Microscopia Eletrônica de Varredura - MEV}

Em seguida foi averiguada a microestrutura do corpo de prova. Para isso, foi utilizado um MEV da marca Hitachi, modelo TM3000. Nesta análise foram verificadas as amostras embutidas em baquelite e as 
fraturadas, onde as mesmas foram analisadas por um detector de elétrons secundários.

\section{Dureza Rockwell}

Foi empregado um durômetro marca Pantec, modelo RANS-RS, pertencente ao UniFOA, onde é possível averiguar a Dureza Rockwell Normal, a dureza Rockwell Superficial e Brinel. Especificamente neste experimento, foi utilizada a Dureza Rockwell Normal. Fez-se necessário para o início da utilização do durômetro, a colocação de um contrapeso com carga equivalente a análise a ser gerada e também se fez necessário a execução de uma pré-carga de 10 $\mathrm{kg}$ de massa para sustentar o corpo de prova (CP). O equipamento durômetro é constituído de um penetrador de esfera 1/16", de aço temperado, e $100 \mathrm{kgf}$ de carga.

\section{Resultados}

\section{Ensaio de Tração}

Os valores de limite de escoamento ( $\sigma \mathrm{y})$, deformação $(\Delta \mathrm{L})$ e resistência à tração $(\sigma \mathrm{t})$, para cada corpo de prova, foram obtidos realizando-se ensaios de tração, como apresentado na Figura 1.

\section{Microdureza Vickers (HV)}

A Figura 2 apresenta o gráfico referente ao ensaio de microdureza Vickers (HV) com suas respectivas cargas de 300 gf e 500 gf.

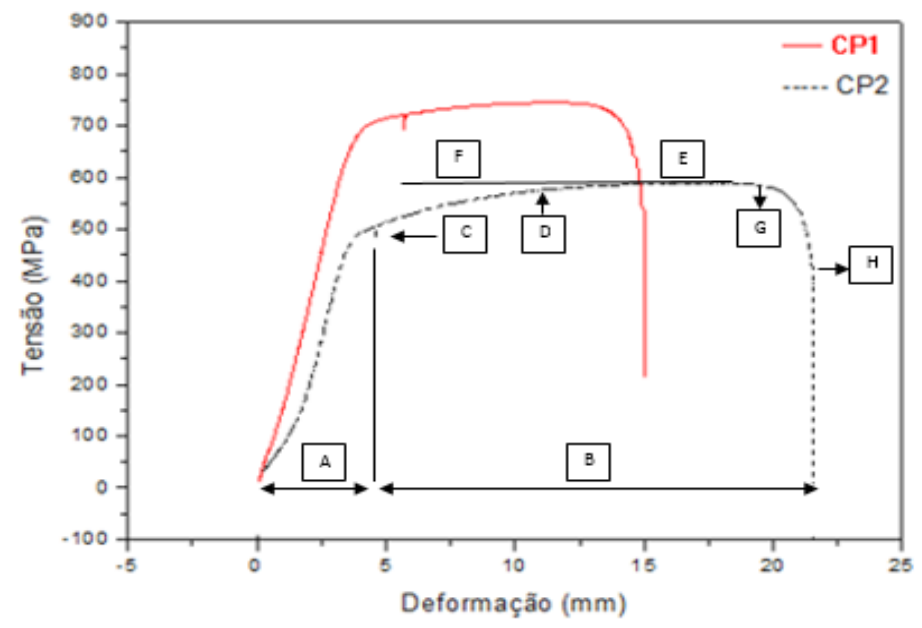

Figura 1. Tensão (MPa) x Deformação (mm).

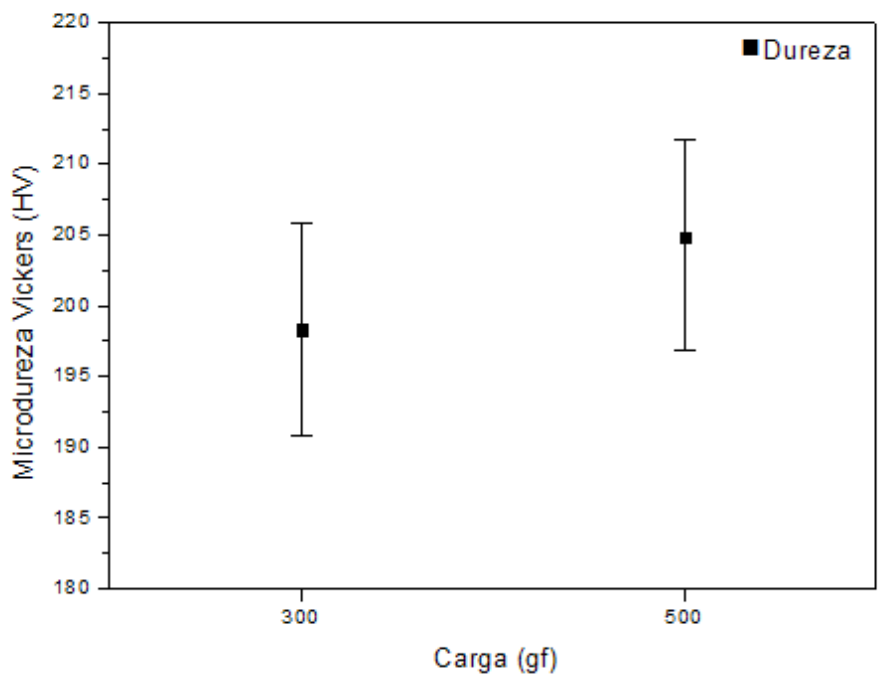

Figura 2. Gráfico teste de dureza Vickers (cargas de 300 gf e 500 gf). 


\section{Microscopia Óptica (MO)}

As microestruturas do material foram reveladas no microscópio óptico e os resultados apresentam microestruturas típicas de um aço baixo carbono hipoeutetoide, com a presença de ferrita $\alpha$ em maior quantidade, que é a fase de cor clara, e perlita em menor quantidade, que é a parte escura, conforme ilustração da Figura 3(a).

\section{MEV}

As Figuras 4 (a) e (b) apresentam uma microestrutura ferrítica com alguns pontos de perlita situados nos contornos de grãos.

A Figura 5 demonstra a microscopia gerada pelo MEV no laboratório do UniFOA com ampliações de 3000x e 5000x, respectivamente, em duas áreas distintas do corpo de prova.

A Figura 6 foi gerada pelo MEV com ampliações de 1000x, 3000x e 5000x, respectivamente, na mesma área do corpo de prova. Nota-se, também, que há formação de inúmeras cavidades que caracterizam uma fratura dúctil.

A Figura 7 mostra a imagem de MEV, com ampliações de 1000x, 3000x e 5000x, respectivamente, em outraárea do mesmo corpo de prova. Pode-se observar novamente a presença de micro fendas mostrando várias cavidades que caracterizam uma fratura dúctil.

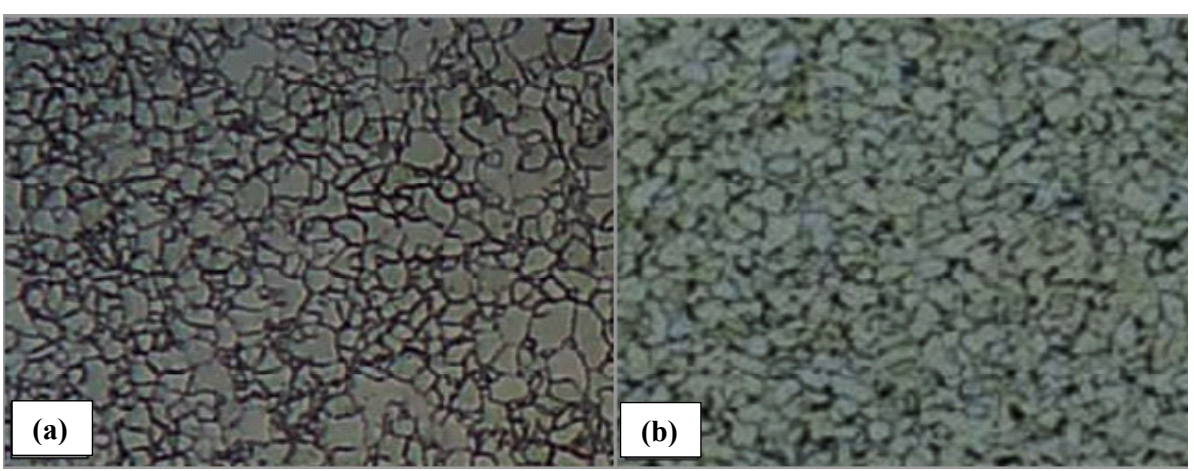

Figura 3. (a) Micrografia do aço SAE 1010 em aumento de 400x, com a presença das fases ferrita (clara) e perlita (escura); (b) Microestrutura aço SAE 1010.

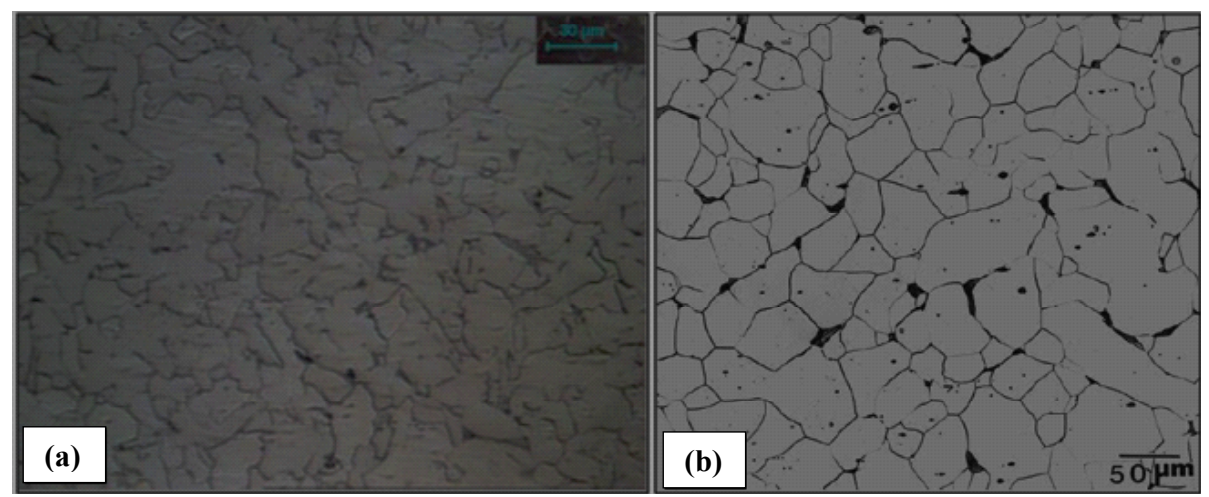

Figura 4. Microestrutura do aço SAE 1010 obtida no microscópio óptico (a) com aumento de 500x; (b) com aumento de 200x. 


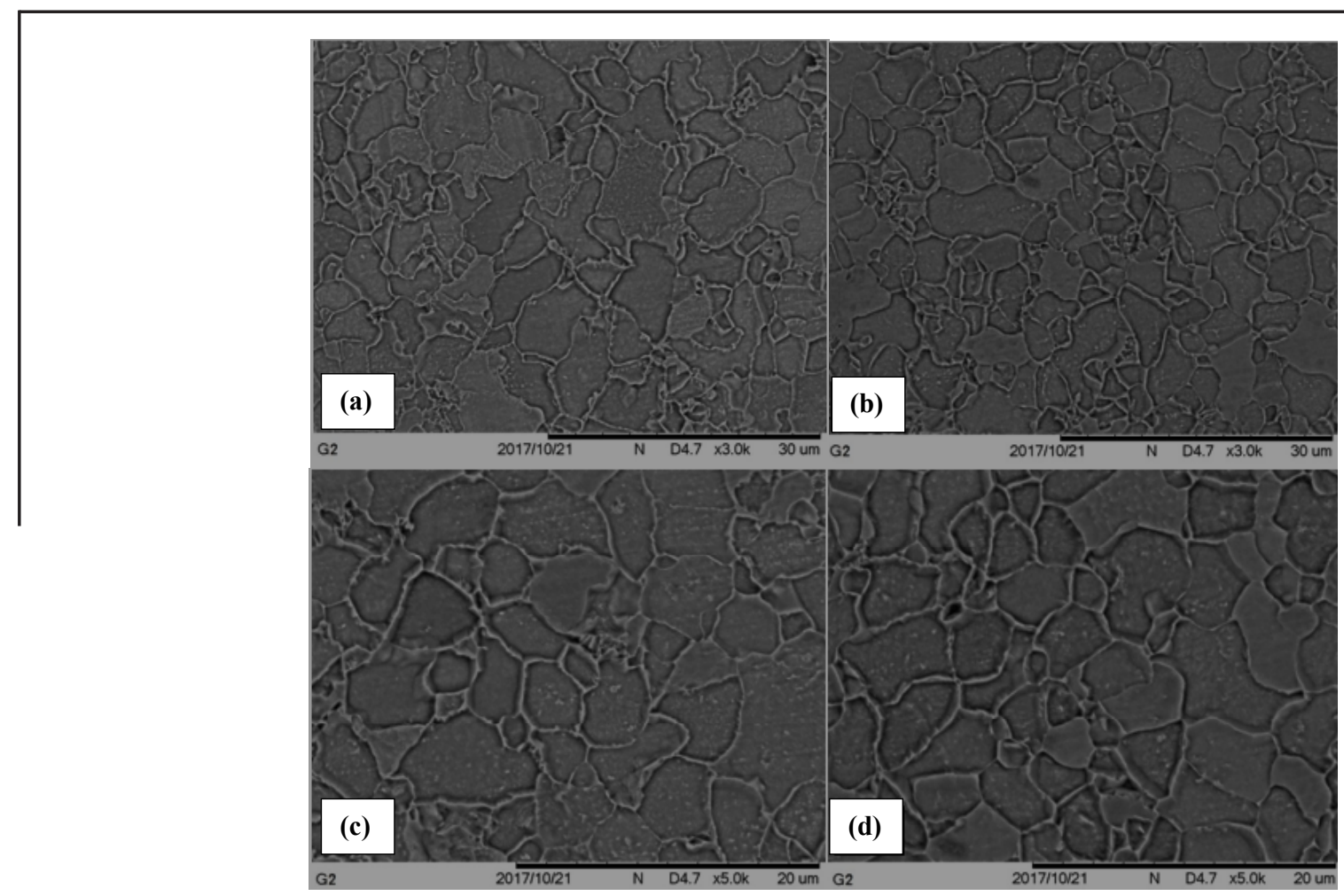

Figura 5. Microscopia MEV: (a) Área 1 3000x; (b) Área 2 3000x; (c) Área 1 5000x; (d) Área $25000 x$.
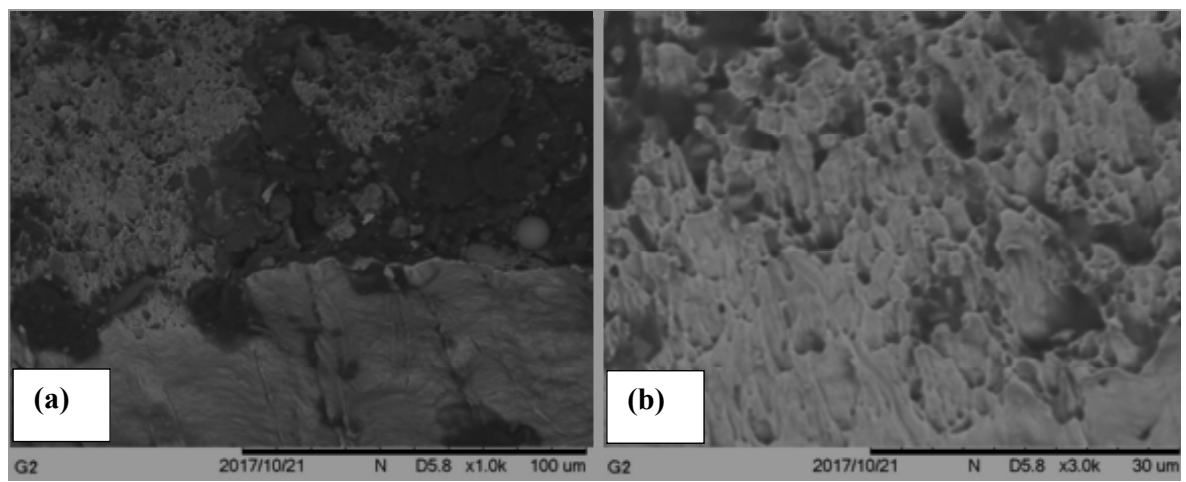

Figura 6. Microscopia MEV: (a) 1000x; (b) 3000x.
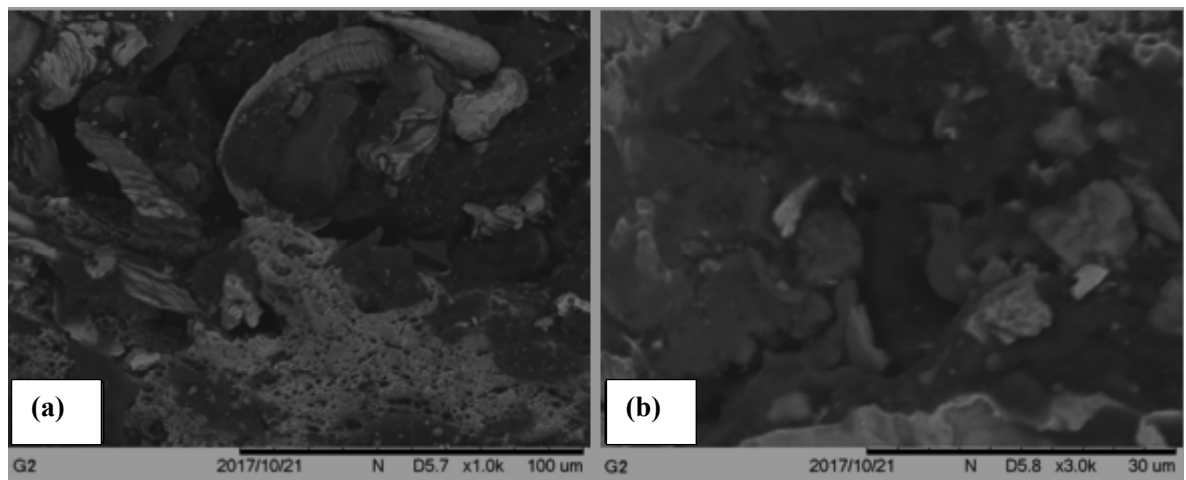

Figura 7. Microscopia MEV: (a) 1000x; (b) 3000x. 


\section{Dureza Rockwell}

Os resultados das indentações foram respectivamente 100, 99 e 99 HRB. A Figura 8 mostra a média calculada para um intervalo de confiança de $95 \%$ com os intervalos calculados em função do desvio padrão individuais

\section{Discussões}

\section{Ensaio de Tração}

Observa-se um comportamento no gráfico de tensão $\mathrm{x}$ deformação com valores compatíveis com os mesmos esperados para um aço com baixo teor de carbono SAE 1010, conforme resultados apresentados por Lima et al. (2017). De acordo com a Figura 1, e tomando como referência o teste realizado no corpo de prova 2, pode-se destacar: A-Zona Elástica, B-Zona Plástica, C-Região de Deslocamento de Discordância, D-Região de Encruamento Uniforme, E-Início de Ruptura, F-Limite de Resistência à Tração, G-Região de Encruamento não Uniforme e H - Ruptura do Material. Pode verificar que houve diferenças nos valores de tensão de escoamento e última entre os dois corpos de prova, fato este que pode estar associado ao seu processo de usinagem, conforme a pesquisa de Lima et al. (2017).

\section{Microdureza Vickers (HV)}

Segundo Guerra et al. (2017), em estudo comparativo entre o aço Norte Americano SAE 1010 e o Europeu C10C, cujas as composições químicas são similares, a dureza média de um aço SAE 1010, testado com carga de 100 gf, está em torno de $210 \mathrm{HV}$. Segundo os autores, pequenas diferenças na microdureza podem ser justificadas pelo processamento termomecânico de cada material. Na presente pesquisa, é possível constatar que não houve mudança nos valores de microdureza entre os resultados oriundos das medias nas cargas de 300 e 500 gf, quando leva-se em consideração o intervalo dos seu respectivos desvios padrões. E desta forma, fica comprovado que o material apresenta boa homogeneidade superficial.

\section{Microscopia Óptica (MO)}

Conforme demonstrado por Guerra et al. (2017), na Figura 3(b), a microestrutura revelada é compatível com a microestrutura de um aço com baixo teor de carbono SAE 1010, composta principalmente por uma matriz ferrítica e perlita nos contornos de grãos.

\section{MEV}

As micrografias das Figuras 4 (a) e (b) apresentam aspectos esperados de serem encontrados em um aço SAE 1010. Tais aspectos também foram descritos por Baptista e Versuto (2011) em pesquisa realizada em aço com baixo carbono $(0,1 \%)$, observa-se uma microestrutura ferrítica (constituinte de fase branca) com alguns pontos de perlita (constituintes de fase escura) situados nos contornos de grãos.

Na Figura 5 observa-se que os valores encontrados na microscopia gerada pelo MEV, estão em acordo com esperado comparando-se com os aspectos ilustrativos de ferrita e perlita mostrando uma grande predominância de ferrita e pequenos pontos de perlita nos contornos de grãos (partes mais escuras), conforme descrito por Colpaert (1983).

Segundo Celik, Gasan, Ulutan \& Saygin (2009), em seu experimento constatou-se que as microfendas no aço SAE 1010 existiam apenas na área que não sofreu tratamento térmico mostrando que o material é mais dúctil, A Figura 6 gerada pelo MEV com ampliações de 1000x e 3000x, mostra que há formação de inúmeras cavidades que caracterizam uma fratura dúctil.

Segundo Chiaverini (2008), o ferro puro, composto só de ferrita, por exemplo, denota-se dúctil, mole, com pouca resistência à tração e alta resistência ao choque. A presença de microfendas, conforme mostrado nas Figuras 7 (a) e (b), a qual apresenta várias cavidades, caracterizam uma fratura dúctil. Esse comportamento mostra que o material não sofreu tratamento térmico, pois a grande quantidade de ferrita presente no material contribui para uma maior ductilidade.

\section{Dureza Rockwell}

A Figura 8 comprova que a média das três medidas encontradas apresentaram valores, com baixo desvio padrão, o que denota um material com excelente homogeneidade superficial e assim, compatíveis com valores esperados em testes realizados em metais macios, conforme Zaiden \& Pettersen (2010).

\section{Considerações finais}

Por meio de ensaios de tração executados nos corpos de prova, foi possível identificar e conhecer, de forma clara, os materiais dúcteis e suas propriedades mecânicas. Estes ensaios foram bem-sucedidos e demonstraram, didática e objetivamente, a fase de ruptura de um aço que é facilmente encontrado em várias áreas do setor mecânico e automobilístico. Em virtude 


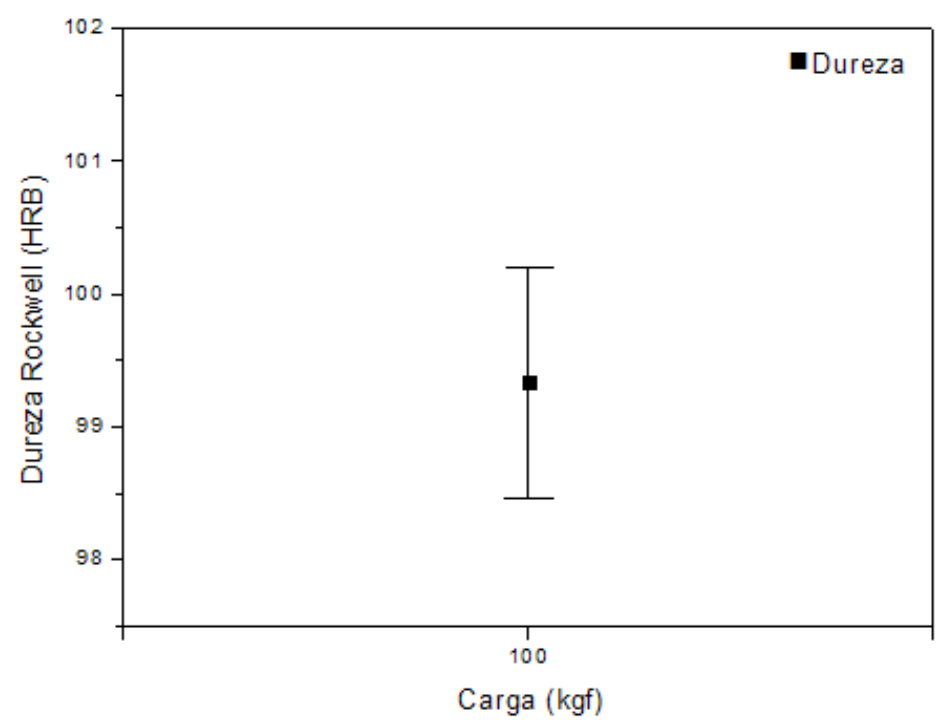

Figura 8. Gráfico do teste de dureza Rockwell com pré-carga de 10 kgf e carga de $100 \mathrm{kgf}$.

ao bom resultado alcançado, não foram identificadas prováveis fontes de erros nas informações obtidas.

Foi possível também conhecer o comportamento deste aço durante o ensaio prático. $\mathrm{O}$ corpo de prova $\mathrm{CP} 1$ apresentou limite de escoamento de $648 \mathrm{MPa}$, resistência à tração de $745 \mathrm{MPa}$ e deformação de $14,95 \mathrm{~mm}$. Já o corpo de prova CP2 apresentou limite de escoamento de $471 \mathrm{MPa}$, resistência à tração de $589 \mathrm{MPa}$ e deformação de $21,57 \mathrm{~mm}$.

A dureza média alcançada nos ensaios de microdureza Vickers foi de 198,29 HV para uma carga de 300 gf e 204,83 HV para uma carga de 500 gf.

A amostra apresentou aparência superficial conforme o esperado para o aço analisado, SAE 1010, ou seja, uma microestrutura com uma matriz ferrítica com pequenos pontos de perlita nos contornos de grão.

Os resultados alcançados nos ensaios de tração e da análise da fratura no MEV demonstraram que o material é muito dúctil, características típicas de um aço SAE 1010 sem nenhum tratamento térmico.

\section{Referências Bibliográficas}

ASM International (2002). Metallographer's Guide: Irons and Steels. USA.

ABNT NBR NM 188-1 (1999). Materiais Metálicos - Determinação da dureza Vickers, São Paulo.

ABNT NBR 6152 (2002). Materiais Metálicos: Ensaio de Tração à Temperatura Ambiente. Rio de Janeiro.

Baptista, C.A. R. P. \& Versuto, B. C. B. (2011). Mechanical and Microstructural Characterization of Flash-Welded Joints in HSLA Steels, 21st Brazilian Congress of Mechanical Engineering Natal-RN, October 24-28.

Celik, O. N., Gasan, H., Ulutan, M. \& Saygin M. (2009). An investigation on fatigue life of borided AISI 1010 steel. Journal of Achievements in Materials and Manufacturing Engineering, 32 (1), 13-17.
Chiaverini, V. (2008). Aços e Ferros Fundidos. $7^{\mathrm{a}}$ ed. São Paulo, Associação Brasileira de Metalurgia e Materiais.

Colpaert, H. (2008). Metalografia dos Produtos Siderúrgicos Comuns, $4^{\mathrm{a}}$ ed. Edgard Blucher.

Dieter, G.E. (2000). Mechanical Metallurgy. 5th Edition; Singapore. Mcgraw-Hill Book.

Guerra, G., Figueroa-López, U., \& Guevara-Morales, A. (2017). Compression Behavior of DIN C10C and SAE-AISI 1010 Steels During Riveting of Clutch Disc Spacer Bolts: Experimental and Computational Analysis. SAE International Journal of Materials and Manufacturing, 10 (2), 123-129.

Portal Mecânica Industrial. Disponível em $<$ https://www.mecanicaindustrial. com.br/481-diferentes-utilizacoes-do-aco-com-baixo-teor-de-carbono/>. Acesso em 28 de outubro de 2017.

Lima, A. V. F., Leite, S. S., Garcia, B., Marques, C. Z., Gandra, C. J., Naitzke, D. A. C. C., Scarpin, L. M. \& Santos, P. S. B. (2017). Ensaio de Tração e Metalográfico do Aço SAE 1010. Revista Engenharia em Ação UniToledo, 2 (1), 69-59.

Zaiden, A. R., Pettersen, L. P., Oliveira, S. G. (2010). Ensaios Mecânicos de Metais. Universidade Federal de Uberlândia Faculdade de Engenharia mecânica. 